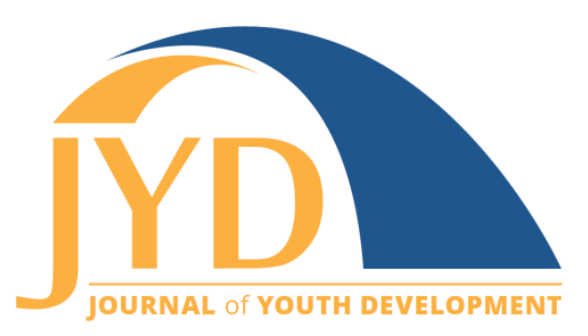

http://jyd. pitt. edu/ | Vol. 14 Issue 4 DOI 10.5195/jyd.2019.641 | ISSN 2325-4017 (online)

\title{
Promoting Pro-Social Skills to Reduce Violence Among Urban Middle School Youth
}

\author{
Deb Risisky \\ Southern Connecticut State University \\ risiskyd1@southernct.edu \\ James MacGregor \\ Southern Connecticut State University \\ macgregorj1@southernct.edu

\section{Deborah Smith} \\ Southern Connecticut State University (retired) \\ smithd17@southernct.edu \\ Jamie Abraham \\ Tufts University \\ jamieabraham8@gmail.com
}

MaryJo Archambault

Southern Connecticut State University

archambaulm2@southernct.edu

\begin{abstract}
Adolescent violence is a significant public health problem. The goal of this evaluation was to determine whether communication skills, relationships with adults, and relationships with peers were enhanced through participating in an after-school program aimed at reducing violence-related behaviors among urban middle school youth. Elements that helped to foster success among our population were providing a program that enabled consistent choice in recreational activities in a safe place, and also providing busing home to increase safety. A non-experimental study was conducted with 115 students who participated in the program. Bivariate, ANOVA analysis, and Kruskal-Wallis tests were carried out. Results indicated that participating in the program significantly impacted student relationships with adults and their peers as well as positively impacted their communication skills. The program was designed with purposeful activities that would address pro-social behaviors, enhance youth interest, and increase
\end{abstract}

(c) EY New articles in this journal are licensed under a Creative Commons Attribution 4.0 License. This journal is published by the University Library System, University of Pittsburgh and is cosponsored by the University of Pittsburgh Press. The Journal of Youth Development is the official peer-reviewed publication of the National Association of Extension 4-H Agents and the National AfterSchool Association. 


\section{After-School Violence Prevention Program}

attendance. The program specifically used recreation to help foster relationships with their peers and the adults in the program, with the intention of reducing conflict, and therefore violence among the students.

Key words: after-school program, youth violence, recreation programs

\section{Introduction}

\section{Youth Violence Behaviors}

Adolescent violence is a significant public health problem. The impact of violence goes beyond the students directly impacted to include their families, school peers, and the community in which they live (Centers for Disease Control and Prevention [CDC], 2019a; CDC, 2019b). The violence behaviors can be committed by an adolescent or against an adolescent and include actions such as assault by physical force or by weapon as well as bullying. These actions can occur in school or community settings, including the youth's home (CDC, 2019a; Children's Safety Network, 2017).

Prevalence of adolescent youth violence can be difficult to attain, as many violence behaviors often go unreported. In the most recent version of the CDC's Youth Risk Behavior Surveillance Survey among high school youth, over 1 in 5 students reported being in a physical fight in the previous year; males had double the rates compared to females, with close to $30 \%$ of males and $15 \%$ of females reporting being in a physical fight. School-related violence was high, with $16.2 \%$ of students reporting they had carried some type of weapon to school in the previous month and $5.6 \%$ of students not going to school at least once in the previous month due to feeling unsafe either at or coming/going to school (Eaton et al., 2012; Kann et al., 2016). With high prevalence of violence seen among adolescents in high school, prevention programs need to start earlier - at least by middle school - to lessen violence as adolescents age.

\section{Risk and Protective Factors for Youth Violence}

A number of risk factors increase the likelihood of adolescent violence. These can be divided into individual risk factors, peer risk factors, and social/environmental risk factors. Individual factors include drug, alcohol or tobacco use; poor grades in school; early aggressive behavior; previous history of victimization; poor behavioral control; emotional distress; and family exposure to violence and conflict. Peer risk factors include relationships with peers that engage in problem behaviors, involvement in gangs, poverty in the community and/or family, antisocial behavior, school violence, and urban settings (CDC, 2017). 


\section{After-School Violence Prevention Program}

Social/environmental risk factors often are related to the community and include factors such as limited or deprived resources, social disorganization of the community, high concentration of families in poverty, and family transiency. These are all factors that can increase risks of youth violence (Butcher, Galanek, Kretschmar, \& Flannery, 2015). Poverty is associated with chronic stress of family members, which can lead to discord or decreased parental coping behaviors (Eamon, 2001). Children are susceptible to internalizing and externalizing the violence they are exposed to in their communities or homes, and are more likely to present conduct issues than youth not in violent areas (McCabe, Lucchini, Hough, Hazen, \& Yeh, 2005). In fact, it is estimated that approximately $40 \%$ of inner-city youth are exposed to a shooting and many more youth report exposure to less serious forms of community violence (Stein, Jaycox, Kataoka, Rhodes, \& Vestal, 2003).

Family status and achievement in school have been found to be protective factors against youth aggression or other problem behaviors. As the amount of education a parent has completed increases, family functioning tends to increase. In many cases, more educated parents and overall better family functioning contribute to the emotional foundation for youth development (Gorman-Smith, Tolan, Henry, \& Florsheim, 2000). Youth educational achievement is associated with positive, protective factors such as motivation, higher self-esteem and adult support (Dubow, Huesmann, Boxer, \& Smith, 2016; Gorman-Smith et al., 2000; Jolliffe, Farrington, Loeber, \& Pardini, 2016). Relationships with adults positively influence children regarding engagement in school, which can lead to increased academic achievement and foster other protective factors (Anderson, Christenson, Sinclair, \& Lehr, 2004).

\section{After-School Programs}

Literature supports the use of after-school programs that focus on positive youth development as a means to help reduce the number of incidents of youth violence. More children and adolescents are attending after-school programs today than ever before. Youth participation in after-school programs increased by nearly 60\% between 2004 and 2014, with approximately four million children attending an after-school program in 2014 (Afterschool Alliance, 2014). Youth engagement in structured and supportive out-of-school and recreational opportunities are related to both their positive development and decreased involvement in delinquency and substance abuse (Durlak \& Weissberg, 2007; Gottfredson \& Wilson, 2003; Witt \& Caldwell, 2010). Organized activities are important contexts that help young people build competencies and successfully negotiate the salient developmental tasks of childhood and adolescence. 


\section{After-School Violence Prevention Program}

There are many benefits to participation in after-school programs for at-risk youth. They can impact the student's academic achievement, reduce risk for participating in delinquent/criminal activity, and also address pro-social development of behavior and improving school attendance and engagement (Kremer, Maynard, Polanin, Baughn, \& Sarteschi, 2015). After-school programs work to improve relationships between students and supportive adults, promote school engagement, and foster healthy peer interactions. After-school programs also attract children through activities; children are able to participate in organized and supervised games, and are also prevented from engaging in negative behavior after school (Fraser-Thomas, Cote, \& Deakin, 2005). Supervision is an important component that makes after-school programs successful; since many youth risk factors are associated with disorganization or unsupervised time, it is necessary to address this issue (Goldstein, Davis-Kean, \& Eccles, 2005; Olsen \& Kowalski, 2010). The supervision that after-school staff provides enhances children's feeling of safety and improves the overall environment of the program (Olsen \& Kowalski, 2010).

After-school programs can be used as a violence prevention strategy if they are developed and structured in ways that influence and shape youth capacity in positive ways, and not just used to occupy the unsupervised hours of 3 p.m. to 6 p.m. Several evidence-based youth violence prevention strategies have recognized that after-school programs are settings which provide students with safe spaces to strengthen social relationships, develop skills and competencies to choose non-violent behaviors, and build and maintain healthy and safe relationships with caring adults in their community (David-Ferdon \& Simon, 2014; Kim, Gilman, Hill, \& Hawkins, 2016).

\section{Overview of the Program}

Creative interventions are necessary when working with children, and after-school programs have been a successful approach. The assets-building model of positive youth development (Eccles \& Gootman, 2002), was used as the framework to guide in the design, implementation and evaluation of the after-school program in this evaluation. Key elements of the recreationoriented programming included components intended to provide and facilitate safety, social belonging and relationship building, self-esteem and skill building, and self-actualization. Recreation activities are powerful social tools for incubating in youth the ability to negotiate with peers, resolve conflict, and work together for communal goals (Witt \& Caldwell, 2010). They have the added benefit of being things that young people willingly choose to do. Therefore, recreation was used as the lynchpin for attendance and participation in the afterschool program. 


\section{After-School Violence Prevention Program}

An emphasis on safety, both environmental and programmatic, was deemed imperative to program success. A baseline model assumption was that it is difficult to achieve scaffolding objectives such as building social networks, improving life skills, and achieving actualization when the perception of safety is absent. Structural program features and characteristics relating to safety included organized and supervised transitions from classrooms to the after-school program; procedures in place for supervised flow of participants from one program location to another, and supervision during all program activities. The program also had procedures in place for taking attendance and informing parents of students who attended school but were not at the program.

The curriculum was deliberately designed to achieve specific outcomes. Social belonging and relationship building were facilitated by offering opportunities for students to increase social interactions and to develop friendships with peers and staff members. Activities used to address relationship building included a variety of team sports and creative arts such as creating murals. Recreation was the centerpiece of the program because it served not only as a hook to encourage participation but also as a powerful social tool for accomplishing specific objectives. Program participants were given the freedom to choose their daily activities. Every day program participants were able to select from a menu of choices that always included a physical, creative, and educational option. A program priority was to offer options that the young people had not experienced before, with the intention of expanding their world. This was considered to be an important program structure statement because it supports the premise that youth are essential players in their own development. A portion of the after-school program was dedicated to students completing homework to reinforce the importance of education and facilitate progression to the next grade.

\section{Program Implementation}

The program was offered for 3 consecutive years with the first and second years serving as pilot years. The pilot years were used to identify the program model, determine program structure, test recreational activities for effectiveness and participant interest, pilot the evaluation instrument, and determine effective strategies for staff training. Based on the evaluation and evolution of the program during years 1 and 2, the program was fully operationalized at the beginning of year 3 . 


\section{After-School Violence Prevention Program}

Funding for the program was awarded by the Institute for Municipal and Regional Policy at Central Connecticut State University as part of a state-funded initiative to provide communitybased youth violence prevention activities. The two schools that housed this program were selected because they serve a population with historically poor scholastic achievement and demographics indicating a very high percentage of at-risk youth. In this school system, $49 \%$ of the population are considered low income; the population of those ages 0-17 living in lowincome housing is $61 \%$ and $60 \%$ of the public $\mathrm{K}-12$ students have at least one high-needs status, such as a parent who is incarcerated, living with other non-parent custodial family members, or living in a home where English is not spoken by the parents. The suspension rate at the schools was nine percent, which was 8 times higher than the nearby suburban district.

The school district does not have traditional elementary and middle schools; instead, there are many K-8 schools that act as a magnet system. The larger of the two participating schools had 197 students in the participating grades, while the smaller school had 163 in the participating grades. Both schools are within blocks of each other, sharing many neighborhood traits. Program participants included students in grades 5 through 8 who were offered the opportunity to voluntarily sign up to participate in the after-school program. An emphasis was first placed on attracting students in upper grades $\left(7^{\text {th }}\right.$ and $\left.8^{\text {th }}\right)$, then students in Grade 6 and Grade 5 were offered the opportunity to sign up and participate in the program.

After-school busing was provided 3 of the 5 program days per week for those who lived a distance away or felt unsafe walking home. Parent pick-up was mandatory for those living in close proximity to the school who did not ride the bus. Only those who submitted signed permission slips were allowed to attend and participate in the program. Finally, a low staff-toparticipant ratio of 1:7 allowed for not only a high level of supervision but also relationship building, which is an important context for feelings of safety. Program opportunities were structured so as to allow students to release stress and to take risks without fear of failure, including participating in non-traditional sports such as rugby, creative arts, and pet therapy.

The program was delivered in partnership between a local university and school district. The lead participant from the university was an academic department specializing in recreation and youth development; both faculty and students were instrumental in design and implementation of the program. A faculty member and students from the university's Therapeutic Recreation concentration oversaw a creative arts program focused specifically on building emotive skills. Specialists in various sport and art programs were brought in to lead and facilitate participation in their specialties. Several teachers from the selected K-8 schools provided specialized program 


\section{After-School Violence Prevention Program}

instruction during the after-school program to reinforce relationships cultivated during the school day.

Other university academic departments that contributed to the success of this project included Social Work, with a student intern on-site 4 days a week to build relationships with the youth, provide more in-depth conflict resolution, and conduct a once-a-week program with the older youth focused on preparation for high school and strategies for dealing with problems and issues that may arise in the transition to high school. The program evaluator was from the Public Health program and specialized in program evaluation. The campus collaboration was intentional, to promote a holistic approach to youth development and these partnerships facilitated building youth from a multi-disciplinary perspective.

The program used the power of role models and mentors: program recreation leaders were current students in the Department of Recreation and Leisure Studies. The program coordinators were recent graduates from the same department. Recreation students served as powerful role models for, and mentors of, the youth. Many of the college student staff mentors came from communities and schools similar to the program intervention site. This commonality created an environment where program participants were receptive to student mentors sharing their experiences and saw modeling that college was a possibility for them. Additionally, it allowed the student participants to trust the words and encouragement shared by the mentors because they were similar. Diversity was represented by the staff in terms of gender, race/ethnicity, and interest; several of the staff members were current collegiate athletes.

\section{Purpose of Study}

The purpose of this project was to design a structured, outcome-focused, recreation-oriented, after-school program for high-risk youth, and contribute evidence that after-school programs are safe environments that nurture social connections and build life skills. More specifically we asked:

- Does providing safe after-school programming impact urban youth development of pro-social behaviors, specifically positive communication skills and relationships with adults and peers?

- How are these behaviors impacted by participation rate (attendance)?

- How are these behaviors impacted by school personnel's assessment of student school-time behavior? 


\section{After-School Violence Prevention Program}

\section{Methodology}

A non-experimental design was used for this study using previously collected program evaluation data for mandatory program grant reporting. These data were utilized for a secondary analysis in order to look at program impact in more depth. There were a total of 115 students in the program across two participating schools who were included in this study. To be included in the study, students had to be active participants in the program at the end of the year when the instruments were administered. This was an important criterion because program staff needed to fill out a behavioral instrument, which required ample time for observation and development of a clear understanding of participant behavior. School A ( $n=$ 78) was in the third year of program implementation and included fifth grade students, as requested by the school. School B $(n=37)$, in their first year of implementation, was limited to sixth through eighth grade students. This study had approval from the research team's Institutional Review Board.

\section{Measurement}

\section{Program Outcomes}

To capture program impacts on youth behaviors and skills, the SAYO-S: Survey of Academic and Youth Outcomes - Staff was used. This questionnaire is designed to measure "eight outcome areas that research suggests are linked to long-term positive development and academic and life success in after-school program youth" (Miller \& Surr, 2011). It was designed and tested by the National Institute on Out-of-School Time (NIOST) at the Wellesley Centers for Women at Wellesley College in Massachusetts and has been noted to have strong validity by additional sources (Wilson-Ahlstrom, Yohalem, DuBois, Ju, \& Hillaker, 2014).

The eight scales of the SAYO-S measure the following areas using a 5-point scale, from 1 (never) to 5 (always). The areas are behavior, initiative, engagement in learning, problem solving skills, communication skills, relations with adults, relations with peers, and homework (Miller \& Surr, 2011). Each of these eight scales has between four and eight specific items for the staff to rate for each youth. The communication skills, relations with adults, and relations with peers domains were selected to measure desired outcomes of the program.

Program leadership participated in the online training modules as required by NIOST in order to complete the survey for each participant. Both program coordinators received detailed training by the program director in how to utilize the instrument. Using an attendance list, the program 


\section{After-School Violence Prevention Program}

coordinators completed one questionnaire for each student at their program site. The program coordinators oversaw the program, including the student recreation leaders who ran activities, and were there every day of the program. The program coordinators knew each student from the students' daily participation; both program coordinators had been with the program as recreation leaders during previous years of implementation. Only the program coordinators completed the form for all participants at their site; this was done to increase reliability. The forms were completed at the university office, under the supervision of the program director, to limit distractions and ensure completion and accuracy.

\section{Student Perceptions of Safety}

To capture student perceptions of safety, a pretest/posttest was used. This instrument was used primarily as a means to identify student perceptions of a variety of factors: their views of participating in the program, views on violence in their lives, perceptions of their own behaviors, and factors related to safety. For this study, the five questions related to perceptions of safety were used. These paper instruments were developed specifically for this program and were age-appropriate and culturally sensitive, including a Spanish version. The instrument was used during the pilot test years and adapted for the final year to be comprehensive and address the program and its components.

The program questionnaire was given at the beginning and end of the program over the course of 2 weeks, with three data collection days at each time frame. Participants began the program in classrooms separated by grade and had snacks with at least two recreation leaders present. It was at this time that the instruments were given to the participants by the evaluator. The questionnaires were given on days with the highest participation due to provided busing at the end of those program days. Participants who struggled with the language in the questionnaire (due to English literacy and/or general reading issues) were assisted by team members who read the questions to them. Only those answers from participants who completed both a pretest and posttest ( $n=64$ ) were used for this analysis of the safety perceptions.

\section{Student Characteristics}

An instrument was developed by the program director to gather student information that was not collected through other instruments. This instrument was given to each school principal to complete with the assistance of their school counselor. The form contained six items: student name, student grade, transportation method home from the program, whether the home was 


\section{After-School Violence Prevention Program}

single/no parent, if a parent was currently or previously incarcerated, and a rating of the student's school-based behavior. The first three items were completed by the program staff to ensure all program students were included; the school personnel addressed the remaining three. The program sought to work with high-risk students, including those who had parents who were incarcerated and those who may have presented behavioral problems during the school day. The former variable was intended for use, but too small to analyze. School behavior was used as an independent variable.

\section{Attendance}

On each day of the program, attendance was recorded for each student, with the participants listed by grade. Additionally, students signed up for a variety of activities throughout each program day. The attendance and sign up rosters were used to determine and verify program attendance. These documents were provided weekly to the project's evaluator and reviewed so as to determine any discrepancies in a timely manner.

\section{Data Analysis}

Analysis began with univariate frequencies of the independent variables (attendance, school behavior), safety perceptions, and each item within the selected SAYO-S scales. Cronbach's Alphas were generated for each scale: communication skills $(a=.84)$, relations with adults ( $a=$ $.92)$, and relations with peers $(a=.90)$. For the behavior rating, due to small numbers in the lowest two categories ( $4 \& 5$ ), these categories were combined. For the safety perceptions, only frequencies were determined, as the sample size was too small for advanced analysis. For the SAYO data, a total scale score was created for each of the scales and then mean scores were generated; the communication skills scale had four items (maximum score: 20), relations with adults had six items (maximum score: 30 ), and relations with peers had six items (maximum score: 30 ). Once complete, bivariate analysis was conducted on the mean scores for the SAYO scales against the two independent variables. Normal distribution was reviewed on all output, by independent variable, before further analysis was conducted using ANOVA to determine significant differences. Tukey's honestly significant difference (HSD) post hoc test was used to determine significance within categories. Statistical significance was set at $p<.05$. 


\section{After-School Violence Prevention Program}

\section{Results}

\section{Program Participants}

There were 115 students included in this study. The majority of students were at School A, which was expected due to the additional grade included, larger school size, and that the program was in the third year of implementation at that location. In this year of program implementation, there was additional emphasis on recruiting high-risk students, both those identified as having problematic behavior at school as well as those with at least one parent who was incarcerated. The number of students who had a parent currently incarcerated was very low $(n=7)$ and therefore that data could not be used for further analysis. While overall student behavior at school was positive, almost one quarter of the students were rated as exhibiting moderate to poor behavior during the school day. Table 1 summarizes these participant characteristics.

Table 1. Participant Demographics $(n=115)$

\begin{tabular}{|l|c|c|c|c|c|}
\hline Gender & Male & Female & & & \\
\hline & 59 & 56 & & & \\
\hline School & $\mathbf{A}$ & $\mathbf{B}$ & & & \\
\hline & $\mathbf{7 8}$ & 37 & & & \\
\hline Grade & $\mathbf{5}$ & $\mathbf{6}$ & $\mathbf{7}$ & $\mathbf{8}$ & \\
\hline & 17 & 35 & 31 & 32 & \\
\hline Behavior & $\mathbf{1}$ & $\mathbf{2}$ & $\mathbf{3}$ & $\mathbf{4}$ & Missing \\
\hline & 51 & 29 & 15 & 10 & 10 \\
\hline Attendance & $\mathbf{0 - 2 5 \%}$ & $\mathbf{2 6 - 5 0 \%}$ & $\mathbf{5 1 - 7 5 \%}$ & $\mathbf{7 6 - 1 0 0 \%}$ & \\
\hline & 20 & 36 & 28 & 31 & \\
\hline
\end{tabular}

\section{Perceptions of Safety}

Of the 64 students who completed both the pretest and posttest, general perceptions of safety showed an interesting pattern. Over the course of the year, perceptions of safety increased slightly for all categories. At the posttest, students were also asked about their feelings of safety at the program, which was much higher than all other categories. Interestingly, students who felt safe at the program most of the time was $15.6 \%$ higher than at school, which is the location of the program. Table 2 summarizes the data on students' perceptions of feeling safe. 
After-School Violence Prevention Program

Table 2. Students' Perceptions of Feeling Safe Before and After the Program

\begin{tabular}{|l|l|l|l|l|l|l|}
\hline & \multicolumn{2}{|c|}{ A lot } & \multicolumn{2}{c|}{ Sometimes } & \multicolumn{2}{c|}{ Never } \\
\hline & Pretest & Posttest & Pretest & Posttest & Pretest & Posttest \\
\hline Coming to/from school & $48.4 \%$ & $45.3 \%$ & $45.3 \%$ & $50.0 \%$ & $4.7 \%$ & $1.6 \%$ \\
\hline At school & $46.9 \%$ & $59.4 \%$ & $46.9 \%$ & $35.9 \%$ & $3.1 \%$ & $3.1 \%$ \\
\hline After-school program & NA & $75.0 \%$ & NA & $21.9 \%$ & NA & $1.6 \%$ \\
\hline At home & $82.8 \%$ & $79.7 \%$ & $12.5 \%$ & $15.6 \%$ & $4.7 \%$ & $3.1 \%$ \\
\hline In their neighborhood & $31.3 \%$ & $37.5 \%$ & $48.4 \%$ & $50.0 \%$ & $18.8 \%$ & $10.9 \%$ \\
\hline
\end{tabular}

Note. Pretest and posttest totals do not add up to $100 \%$ due to missing responses.

\section{Outcome Behaviors}

With a program that included instruction and activities focused on forming positive relationships, conflict resolution, and mediation, looking at end-of-program communication skills and relationships could point to program impact on the students. Overall, the total mean scores were similar across the scales. Attendance had a strong impact on our three outcomes. Related to communication skills, scores were higher as participation rates rose (Table 3). High attendance was also linked to higher performance for the relationships with adults scale. While not statistically significant, mean scores were higher among those who attended more regularly with regard to relationships with their peers.

Different from attendance, school-rated behavior was only significant for the relationship with peers scale (Table 3). Those whose behavior was rated as more appropriate during the school day also were rated high for interacting with their peers. While not significant, it was interesting to see that relationships with adults were rated best among the middle categories; those at the top and bottom of the behavior scale were rated lowest for interacting with adults. A similar, non-statistically significant trend was seen in the communication scale. 
After-School Violence Prevention Program

Table 3. Outcome Behavior Scales

\begin{tabular}{|c|c|c|c|}
\hline & $\begin{array}{l}\text { Communication } \\
\text { skills } \\
\text { (Max: } 20 \text { points) }\end{array}$ & $\begin{array}{l}\text { Relations with } \\
\text { adults } \\
\text { (Max: } 30 \text { points) }\end{array}$ & $\begin{array}{c}\text { Relations with } \\
\text { peers } \\
\text { (Max: } 30 \text { points) }\end{array}$ \\
\hline & Mean score & Mean score & Mean score \\
\hline Total participants & 15.02 & 23.12 & 24.88 \\
\hline \multicolumn{4}{|l|}{ Attendance } \\
\hline $0-25 \%(n=20)$ & $13.35^{*, \dagger}$ & $20.30 *, \dagger$ & 23.60 \\
\hline $26-50 \%(n=36)$ & 14.44 & 22.53 & 25.06 \\
\hline $51-75 \%(n=28)$ & $16.00 *$ & $24.39 *$ & 25.71 \\
\hline $76-100 \%(n=31)$ & $15.90 \dagger$ & $23.87 \dagger$ & 24.73 \\
\hline \multicolumn{4}{|l|}{ Behavior** } \\
\hline 1 (high) $(n=51)$ & 14.94 & 22.75 & $25.76 *$ \\
\hline $2(n=29)$ & 15.72 & 23.89 & 25.18 \\
\hline $3(n=15)$ & 14.93 & 24.23 & $22.87 *$ \\
\hline 4 (low) $(n=10)$ & 14.56 & 22.30 & 22.60 \\
\hline
\end{tabular}

Note: Significance within categories determined using Tukey's honestly significant difference (HSD) post hoc test. *Significant at $p<.05$. +Significant at $p<.05 . * * 10$ missing from analysis.

\section{Discussion}

The described after-school program possesses characteristics that enhanced its success with the participating youth. The reported outcomes including students' feelings relating to safety, enhanced relationship building, and communication skills align with similar findings of other after-school programs. Providing a safe haven and supervised time after school, teaching and promoting new skills, and offering opportunities for adult and peer relationships, after-school programs have the potential to curb juvenile crime and positively impact youth development outcomes, both short- and long-term (Kremer et al., 2015). In particular, the significance found in regards to relationship building with both adults and peers is an important factor in promoting pro-social behavior and reducing negative behaviors. One protective influence that distinguishes high-risk youth who succeed in avoiding risk behaviors is their bonding to caring adults and to groups that facilitate successful maturation by providing opportunities for young people to gain a sense of legitimacy (Barnett, 2008). 


\section{After-School Violence Prevention Program}

\section{Implications for Practice}

Programs that include elements of effective youth development have the highest opportunity for success. These elements include a program design that includes activity choices and an encouragement of academic and social achievement, facilitating feelings of safety, relationship building with invested staff, and staff that are highly and regularly trained (Njapa-Minyard, 2010; Roth \& Brooks-Gunn, 2016). Studies have shown that an identified challenge of afterschool programs is attracting and retaining students, so programs must be tailored in an engaging manner given the importance of time spent in the program for facilitating positive behaviors (Njapa-Minyard, 2010).

\section{Program Design}

The current program was deliberately designed and included elements that promote pro-social behaviors in youth. Recreation was used as the hook to enhance youth interest in the program, but buy-in from parents was also deemed an important influence to program attendance. The program included a blend of both traditional and non-traditional (to participants) recreational sports and activities. Program participants were given the opportunity to provide input into the design of the program by completing an activity interest checklist. In addition, the recreational sports and activities that were included in the program were monitored to determine the extent to which they helped foster pro-social behaviors and provided opportunities for skill building. At each program time block, participants were able to select from two to three activity options, encouraging choice throughout the entire program year. Similar to other programs, attendance was enhanced due a blend of academic, recreation, and social activities during a structured time frame (Sanderson \& Richards, 2010).

\section{Feelings of Safety}

The program occurred at two schools located in a high-crime neighborhood of an urban city. Of utmost importance was to provide youth a safe environment to engage in recreational and academic activities, which has shown to be impactful among after-school programs (NjapaMinyard, 2010). Safety was a topic of discussion in all elements of the program design, implementation and evaluation process. Concern for youth safety extended beyond the program and school building, and included traveling home from the program. Our program found that providing busing increased attendance as well as assisted youth in feeling safer during the after-school hours. 


\section{After-School Violence Prevention Program}

\section{Relationships With Adults}

Relationships with adults are an important protective factor against youth problem behavior, as adults can provide support and guidance to youth during challenging times (Gorman-Smith et al., 2000). By hiring college students to serve as recreation leaders, the program was careful to select individuals who had backgrounds and experiences that matched the program participants. Two of our recreation leaders had attended these schools as middle school students. Supportive staff relationships, especially with positive adult role models are integral to a successful program outcomes and positive youth development (Njapa-Minyard, 2010).

Our program had similar improvements in student and staff relationships as other tested afterschool programs that were designed to address important elements including safety, opportunities for skill building, and fostering positive relationships with their peers and supportive adults (Daud \& Carruthers, 2008). It is likely that the consistent supervision and presence of understanding and encouraging adults allowed these connections to grow (Olsen \& Kowalski, 2010). Students who participated more in the program were able to convey their ideas clearly to others, and volunteered to answer questions more often. This aligns with previous findings that communication improved for students in an after-school program; participants interacted with peers and mentors in a more focused environment than their typical classroom, so they had the opportunity to practice effective communication (Daud \& Carruthers, 2008). With these strong relationships in place, youth participants attended the program more often and were able to see more benefits from their participation.

\section{Staff Training}

Selecting the correct staff is important, but our program was structured to ensure these collegelevel staff were consistently trained so as to be prepared for all program aspects, as well as challenges that might arise. All recreation leaders participated in trainings prior to the start of the program, with two follow-up sessions occurring at intervals while the program was operating. Staff trainings consisted of a review of safety procedures, key elements of focus areas for the various recreational sports and activities offered in the program, and evaluation procedures and expectations. Recreation leaders were also trained in the use of mediation as a means to help participants resolve conflicts by a specialist in mediation and conflict resolution who was brought in to provide initial training and follow-up trainings. Mediation training was deemed to be important and influential to program success, including enhanced communication skills among participants. 


\section{After-School Violence Prevention Program}

\section{Limitations}

We were limited in the size of the sample and geographic region of the study; our associations are not causal. We did not have information from the youths' parents or caretakers, and were limited to one instrument with youth feedback. The survey was filled out by one staff member at each site. We have only posttest information for the SAYO. Since there is no pretest and we did not control for confounding variables, we are unable to declare that the differences observed were a result of the after-school program.

\section{Conclusion}

This study found positive outcomes associated with an after-school program designed to address youth development through recreation with an intent that these pro-social behaviors would reduce violence-related behaviors. The program focused on youth in an economically disadvantaged area, with a special emphasis on higher-risk youth. Youth with higher program attendance throughout the year were observed to have significantly better communication skills while at the program and better relationships with adults and their peers. The findings demonstrate the need for structured and purposeful after-school programs for youth residing in economically disadvantaged areas where providing a safe environment allows for the development of pro-social behaviors.

\section{References}

Afterschool Alliance. (2014). America after 3pm: Afterschool Programs in Demand. Washington, DC: Author. Retrieved from http://www.afterschoolalliance.org/documents/AA3PM2014/AA3PM_National_Report.pdf

Anderson, A. R., Christenson, S. L., Sinclair, M. F., \& Lehr, C. A. (2004). Check and connect: the importance of relationships for promoting engagement with school. Journal of School Psychology, $42(2), 95-113$.

Barnett, L. A. (2008). Predicting youth participation in extracurricular recreational activities: Relationships with individual, parent, and family characteristics. Journal of Park and Recreation Administration, 26(2), 28-60.

Butcher, F., Galanek, J. D., Kretschmar, J. M., \& Flannery, D. J. (2015). The impact of neighborhood disorganization on neighborhood exposure to violence, trauma symptoms, and social relationships among at-risk youth. Social Science and Medicine, 146, 300-306. doi:10.1016/j.socscimed.2015.10.013 
Journal of Youth Development | http://jyd.pitt.edu/ | Vol. 14 Issue 4 DOI 10.5195/jyd.2019.641

\section{After-School Violence Prevention Program}

Centers for Disease Control and Prevention. (2017). Youth violence: Risk and protective factors.

Retrieved from https://www.cdc.gov/violenceprevention/youthviolence/riskprotectivefactors.html

Centers for Disease Control and Prevention. (2019a). Preventing youth violence. Retrieved from https://cdc.gov/violenceprevention/youthviolence/fastfact.html

Centers for Disease Control and Prevention. (2019b). Preventing school violence. Retrieved from https://cdc.gov/violenceprevention/youthviolence/schoolviolence/fastfact.html

Children's Safety Network. (2017). Youth violence prevention. Retrieved from http://www.childrenssafetynetwork.org/injury-topics/youth-violence-prevention

Daud, R., \& Carruthers, C. (2008). Outcome study of an after-school program for youth in a high-risk environment. Journal of Park and Recreation Administration, 26(2), 95-114.

David-Ferdon, C., \& Simon, T. R. (2014). Preventing youth violence: Opportunity for action. Atlanta, GA: National Center for Injury Prevention and Control, Centers for Disease Control and Prevention.

Dubow, E. F., Huesmann, L. R., Boxer, P., \& Smith, C. (2016). Childhood and adolescent risk and protective factors for violence in adulthood. Journal of Criminal Justice, 45, 26-31. doi:10.1016/j.jcrimjus.2016.02.005

Durlak, J. A., \& Weissberg, R. P. (2007). The impact of after-school programs that promote personal and social skills. Chicago, IL: Collaborative for Academic, Social, and Emotional Learning. Retrieved from https://casel.org/wp-content/uploads/2016/08/PDF-1-the-impact-of-after-school-programsthat-promote-personal-and-social-skills-executive-summary.pdf

Eamon, M. K. (2001). The effects of poverty on children's socioemotional development: An ecological systems analysis. Social Work, 46(3), 256-266. doi:10.1093/sw/46.3.256

Eaton, D., Kann, L., Kinchen, S., Shanklin, S., Flint, K., Hawkins, J.,

Wechsler, H. (2012). Youth risk behavior surveillance - United States, 2011. Morbidity and Mortality Weekly Report: Surveillance Summaries, 61(4), 1-162. Retrieved from http://www.jstor.org/stable/24806047

Eccles, J. S., \& Gootman, J. A. (2002). Community programs to promote youth development. Washington, D.C.: The National Academies Press.

Fraser-Thomas, J. L., Cote, J., \& Deakin, J. (2005). Youth sport programs: an avenue to foster positive youth development. Physical Education and Sport Pedagogy, 10(1), 19-40. doi:10.1080/1740898042000334890

Goldstein, S. E., Davis-Kean, P. E., \& Eccles, J. S. (2005). Parents, peers, and problem behavior: a longitudinal investigation of the impact of relationship perceptions and characteristics on the development of adolescent problem behavior. Developmental Psychology, 41(2), 401-413. doi:10.1037/0012-1649.41.2.401 


\section{After-School Violence Prevention Program}

Gorman-Smith, D., Tolan, P. H., Henry, D. B., \& Florsheim, P. (2000). Patterns of family functioning and adolescent outcomes among urban African American and Mexican American families. Journal of Family Psychology, 14(3), 436-457.

Gottfredson, D., \& Wilson, D. (2003). Characteristics of effective school-based substance use programs. Prevention Science, 4, 27-38.

Jolliffe, D., Farrington, D. P., Loeber, R., \& Pardini, D. (2016). Protective factors for violence: results from the Pittsburgh Youth Study. Journal of Criminal Justice, 45, 32-40.

Kann, L., McManus, T., Harris, W., Shanklin, S., Flint, K., Hawkins, J., . . Z Zaza, S. (2016). Youth Risk Behavior Surveillance - United States, 2015. MMWR Morbidity and Mortality Surveillance Summary 2016; 65(No. SS-06), 1-174. doi:10.15585/mmwr.ss6506a1

Kim, B. K. E., Gilman, A. B., Hill, K. G., \& Hawkins, J. D. (2016). Examining protective factors against violence among high-risk youth: Findings from the Seattle Social Development Project. Journal of Criminal Justice, 45, 19-25. doi:10.1016/j.jcrimjus.2016.02.015

Kremer, K., Maynard, P., Polanin, B., Baughn, R., \& Sarteschi, J. (2015). Effects of after-school programs with at-risk youth on attendance and externalizing behaviors: A systematic review and metaanalysis. Journal of Youth and Adolescence, 44(3), 616-636. doi:10.1007/s10964-014-0226-4

McCabe, K. M., Lucchini, S. E., Hough, R. L., Hazen, A., \& Yeh, M. (2005). The relation between violence exposure and conduct problems among adolescents: A prospective study. American Journal of Orthopsychiatry, 75(4), 575-584. doi:10.1037/0002-9432.75.4.575

Miller, B. M., \& Surr, W. B. (2011). Survey of academic and youth outcomes-staff edition. Wellesley, MA: National Institute on Out-of-School Time. Available from https://www.niost.org/

Njapa-Minyard, P. (2010). After-school programs: attracting and sustaining youth participation. The International Journal of Learning, 179), 177-181.

Olsen, H., \& Kowalski, C. L. (2010). Enhancing program quality and care through supervision. Afterschool Matters, 37-44. Retrieved from http://www.niost.org/images/afterschoolmatters/ asm_2010_10_spring/asm_2010_10_spring-6.pdf

Roth, J. L., \& Brooks-Gunn, J. (2016). Evaluating youth development programs: Progress and promise. Applied Developmental Science, 20(3), 188-202. doi:10.1080/10888691.2015.1113879

Sanderson, R. C., \& Richards, M. H. (2010). The after-school needs and resources of a low-income urban community: Surveying youth and parents for community change. American Journal of Community Psychology, 45(3-4), 430-440. doi:10.1007/s10464-010-9309-x

Stein, B., Jaycox, D., Kataoka, L., Rhodes, H., \& Vestal, S. (2003). Prevalence of child and adolescent exposure to community violence. Clinical Child and Family Psychology Review, 6(4), 247-264. doi:10.1023/B:CCFP.0000006292.61072.d2 
Journal of Youth Development | http://jyd.pitt.edu/ | Vol. 14 Issue 4 DOI 10.5195/jyd.2019.641 After-School Violence Prevention Program

Wilson-Ahlstrom, A., Yohalem, N., DuBois, D., Ju, P., \& Hillaker, B. (2014). From soft skills to hard data: Measuring youth program outcomes. Retrieved from The Forum for Youth Investment website: https://forumfyi.org/knowledge-center/from-soft-skills-to-hard-data/

Witt, P., \& Caldwell, L. (2010). The rationale for recreation services for youth: An evidenced based approach. Ashburn, VA: National Recreation and Park Association. 